Article

\title{
Influence of System Parameters on Fuse Protection Use in Regenerative DC Drives
}

\author{
Mohammed Redha Qader *, Hedaia Al-Asooly and Isa Salman Qamber \\ University of Bahrain, Applied Studies College, P.O. Box 32038, Bahrain; \\ E-Mails: halasooly@asc.uob.bh (H.A.A.); iqamber@eng.uob.bh (I.S.Q.)
}

* Author to whom correspondence should be addressed; E-Mail: mrqader@eng.uob.bh; Tel.: +97317876066; Fax: +973-1787-683179; Mobile: +973-39659293

Received: 20 April 2009; in revised form: 4 June 2009 / Accepted: 8 June 2009 /

Published: 16 June 2009

\begin{abstract}
Current limiting fuses are widely used to protect the thyristors in DC drive systems. One very important problem is the choice of the correct voltage rating for fuses protecting regenerative DC drives, where many types of fault may occur, which makes fuse protection difficult. In the event of a commutation failure while regenerating, the fuses need to interrupt the loop supplied by the AC and DC voltages acting in series, which is the most difficult case for protection by fuses. In this paper a detailed study of the complete interruption process has been investigated by modeling of arcing process of the fuse protection against the regenerative circuit internal commutation fault. The effect of varying the motor time constant, supply impedance, number of fuses used to clear the fault and DC machine rating on the total transient response is studied. The model of a $200 \mathrm{~A}$ fuse is employed in this study. Fuses in series with both the semiconductor devices (F1) and fuses in AC lines (F2) are considered. Comparison was made between arc energy produced for fuses protecting the regenerative circuit if failure occurs, with the arc energy produced in a standard $\mathrm{AC}$ test in order to investigate the required voltage rating for the fuse.
\end{abstract}

Keywords: fuse; arc; regenerative DC drives 


\section{Introduction}

The fuse has been around in one form or other since the earliest days of electric telegraphs and then later in different forms for the protection of power distribution and other circuits. Like many other devices the fuse has undergone considerable evolution since those early days [1]. The modern High Breaking Capacity (h.b.c) fuse provides economical and reliable protection against over current faults in modern electrical systems. Short circuit are usually due to a catastrophic electrical failure, the resulting root mean square value (r.m.s) of the prospective short circuit current is high, typically more than 10 times the normal full load current of the system. In this case the protective device must limit the energy associated with the fault, which depends upon the value of $i^{2} t$, where $i$ is an instantaneous current.

Due to the economical cost and high speed of operation of the current-limiting fuse, special currentlimiting fuses have been developed to protect semiconductor devices [2]. For the protection of semiconductors with fuses a number of parameters of the devices and fuse need to be considered. Among the parameters there are a number of influencing factors associated with each one. However, current-limiting fuses are widely used to protect the thyristors in DC drive systems. In the event of a commutation failure when regenerating (inverting), the fuses need to interrupt in loop supplied by the $\mathrm{AC}$ and DC voltages acting in series, which is the most difficult case for protection by fuse [3]. The commutation fault is shown in Figure 1. This type of fault will occur if a thyristor that has been conducting fails to turn off. Alternatively, this fault might occur if any thyristor fails to turn on at a specified point which the thyristor assumed to conduct. Special attention must be paid to the current transfer between commutating phases because it may not be successfully completed if it is not started early enough.

Figure 1. Internal commutation fault regenerative circuit.

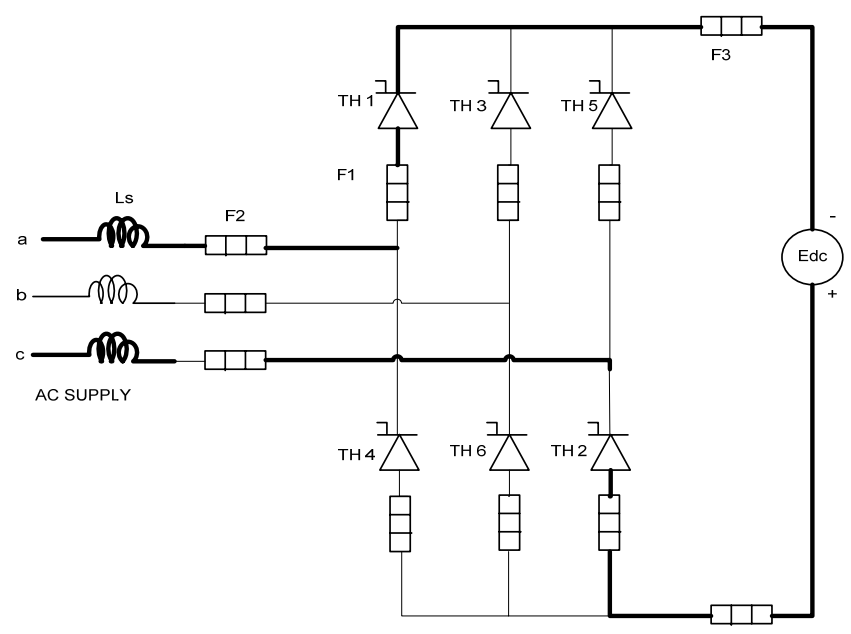

In this paper, a detailed study of the complete interruption process has been investigated by modeling of arcing process of the fuse. The effect varying the motor time constant, supply impedance, number of fuses used to clear the fault and DC machine rating to the total response for fuses protecting against the regenerative circuit internal commutation fault has been studied. The results obtained were 
compared with results in references [4,5], which proved the accuracy of the obtained results. For the validation of the model the results evaluated with reference [6].

\section{The Main Model Used in the Study}

The basic function of the phase-controlled converter is to convert an alternating input voltage to controllable direct output voltage. Considering the 2-qudrant converter shown in Figure 1 consists basically of a conventional rectifier circuit arrangement in all positions of the circuit. Due to the unidirectional current carrying property of the thyristors, the current at DC terminal can flow only in one direction. However, it is possible by suitable control of the phase position of the firing pulses applied to the thyristors with respect to AC input voltage, for the mean voltage at DC terminals to be continuously controlled from maximum positive to maximum negative [7-11]. Thus power can flow either from AC to DC side of the converter, and vice versa, and the converter is capable of workng as an inverter or rectifier.

The average output voltage is given by $V_{d}=1.35 E_{L L} \cos \alpha$ (where $\alpha$ is the firing angle in degree). When $0<\alpha<90, V_{d}$ positive (rectifier mode), while when $90<\alpha<180, V_{d}$ negative (inverter mode). If the 2-quadrant converter is connected to the armature of a DC machine, the polarity of the induced emf of the machine reverses whenever regenerative breaking is required. For example, when the load is being raised, the converter supplies power to machine and the induced emf is positive. On the other hand, when the load lowered, the direction of rotation and induced emf are reversed. Therefore, the polarity of the machine emf is now negative. Consequently, it is in the correct direction for the converter to operate in its inverter region, thus returning regenerative power from machine to AC system [8]. Internal commutation faults will occur if a thyristor that has been conducting fails to turn off. Alternatively, this fault might occur if any thyristor fails to turn at specified point when the thyristor assumed to conduct.

Figure 2. Simplified circuit of Figure 1 if $\mathrm{TH} 1$ and $\mathrm{TH} 2$ are conducting assuming no overlapping.
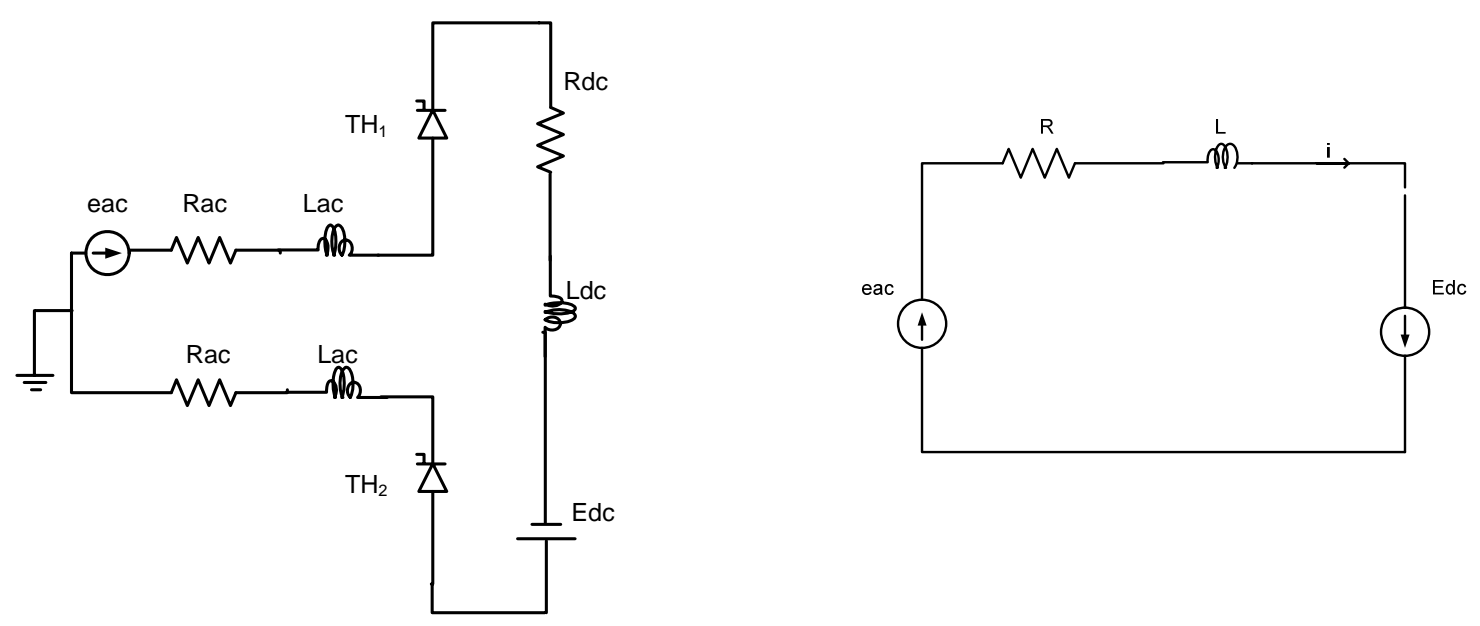
If two thyristors conduct simultaneously, then the line voltage will be applied to the load. If TH1 and TH2 conduct simultaneously, the circuit at this condition will be as in Figure 2. Then the line voltage $e_{a c}$ of Figure 1 is applied across the load, assuming there is no overlapping and also assuming that the thyristors are ideal in that they are dissipationless and have zero voltage drops. Also assuming in the first instance that the commutation fault is due to loss of trigger pulses to all thyristors:

$$
e_{a c}+E_{d c}=\left(R_{a c}+R_{d c}\right) i+\left(L_{a c}+L_{d c}\right) \frac{d i}{d t}
$$

The processes which govern the value of fuse voltage during the arcing period are many and complex, and several simplifying assumption are required in the development of a dynamic fuse model [9]. The fuse is usually several parallel elements and several series notches per element and can be modeled as a cylindrical plasma. The fuse arc voltage during arcing in this study was represented by the following simplified $5^{\text {th }}$ order dynamic model, according to [9]. When the fuse arc voltage is considered during the arcing period:

$$
\frac{d i}{d t}=\frac{\sqrt{2} E_{L L} \sin (\omega t+\theta)+E_{d c}-R i-V_{f}}{L}
$$

The arc voltage is given by:

$$
\begin{gathered}
V_{f}=\left\{\begin{array}{cc}
0 & (\text { prearcing } \\
x E & (\text { arcing })
\end{array}\right\} \\
\frac{d\left(i^{2} t\right)}{d t}=i^{2} \\
\frac{d(\text { arc }- \text { energy })}{d t}=V_{f} i \\
\frac{d x}{d t}=C_{b} i \\
\frac{d A}{d t}=\gamma \alpha \frac{E\left(i_{e}, A\right) i_{e}}{H_{f}} \\
E=\frac{K_{1} i_{e}^{0.4}}{A^{0.85}}+\frac{K_{2} i_{e}^{-0.4294}}{A^{0.5}} \quad K_{1}=4.58 \quad K_{2}=46.8 \\
\alpha=\alpha_{0}+\left(\alpha_{m}-\alpha_{0}\right)\left(1-e^{-t / \tau}\right)
\end{gathered}
$$

Where:

$\alpha_{o}=0.0655, \alpha_{m}=0.63, \tau=0.01 \mathrm{~s}$

$N_{p}=$ Number of parallel elements $=2$

$i_{e}=i / N_{p}=$ Current per element

$A=$ Effective cross-sectional area of lumen (arc channel cross section)

$x=$ Total length of all arcs in series

$H_{f}=$ Fusion enthalpy of sand $\approx 3.614$

$\gamma=$ Filler flow multiplying factor $\approx 0.7$

$C_{b}=$ Kramer constant 
As initial values for solving the differential equations, assuming the notch zones will produce a jump in resistance from zero to $R_{o}$. If the current at the start of arcing is $i_{o}$, the voltage produced is:

$$
v_{o}=i_{o} R_{o} \quad R_{o} \approx 0.05
$$

If the initial arcs channel area $A$ is assumed same as the strip cross section $\mathrm{S}$, then for each subelement the arc gradient will be:

$$
E_{o}=E\left(\frac{i_{o}}{N_{p}}, A_{o}\right)
$$

and the arc length that will satisfy this will be: $x_{o}=\frac{\left\lfloor i_{o} R_{o}\right\rfloor}{E_{o}}$

The transition from pre-arcing to arcing state occurs when the $i^{t} t$ integral reaches the melting value. However in practice, the pre-arcing $i^{t} t$ increases according to: $\left|i^{2} t\right|=\left|i^{2} t\right|_{\min }(1+345 t)$

For the DC side of the converter, the volt-ampere is: $S_{d c}=V_{d} I_{d c}$

For the AC side, the volt-amperes and line current are:

$$
S_{a c}=\sqrt{3} E_{L L} I_{L}, I_{L}=\sqrt{\frac{2}{3}} I_{d c}, V_{d}=1.35 E_{L L}, S_{a c}=1.05 V_{d} I_{d c}, I_{d c}=\frac{P e}{E_{d c}}
$$

When $I_{d c}$ is calculated the minimum permissible fuse rating (MPFR) is evaluated. There are always two fuses in series, either in series with the semiconductor devices or in the AC line. The paper will investigate both locations. The fuse sizes should be at least $125 \%$ of the rms load current. Therefore, the minimum permissible fuse ratings (MPFR) for both locations are:

$$
I_{F 1}=1.25 \frac{1}{\sqrt{3}} I_{d c}, I_{F 2}=1.25 \frac{2}{\sqrt{3}} I_{d c}
$$

Then the fuse ampere rating (FAR) and the melting $i^{t} t$ suitable for the application are found. The model of a $200 \mathrm{~A}$ fuse will be employed in this study. $E_{L L}=460 \mathrm{~V}$, frequency $=60 \mathrm{~Hz}, R_{d c}=0.05$ p.u, $E_{d c}=500 \mathrm{~V}$. Fuses in series with the semiconductor devices (F1) and fuses in AC line (F2) will be considered. If fuse is used in location $\mathrm{F} 1$, that gives certain DC loading condition $I_{d c}=\sqrt{3} .\left(1.25 I_{F 1}\right)$. If fuse is located at F2, this will give a different DC loading condition, $I_{d c}=\sqrt{3} \cdot\left(1.25 I_{F 2} / 2\right)$. The loading conditions for both systems are summarized in Table 1.

Table 1. Summary of the loading conditions.

\begin{tabular}{ccccc}
\hline Location & $\begin{array}{c}\text { DC machine } \\
\text { (HP) }\end{array}$ & $\begin{array}{c}\text { DC full Load } \\
\text { current (A) }\end{array}$ & $\begin{array}{c}\text { Converter rating } \\
\text { (kW) }\end{array}$ & $\begin{array}{c}\text { Fuse ampere } \\
\text { rating (A) }\end{array}$ \\
\hline F1 & 170 & 127 & 270 & 200 \\
F2 & 120 & 90 & 190 & 200 \\
\hline
\end{tabular}

\section{Overall System Transient Response}

Figure 3 shows the internal commutation fault current and the total supply voltage $\sqrt{2} E_{L L} \sin (\omega t+\theta)+E_{d c}$ when no fuse was used to clear the circuit. This is the prospective fault current that the fuses have to interrupt. Figure 4 shows the transient response for total supply voltage, prospective 
current, fuse voltage, arc energy, $i^{2} t$ and arc length x. The figures are obtained for 0.05 p.u supply impedance and $40 \mathrm{~ms}$ DC machine time constant.

Figure 3. The internal commutation fault current and the total supply voltage $\sqrt{2} E_{L L} \sin (\omega t+\theta)+E_{d c}$ when no fuse was used to clear the circuit.

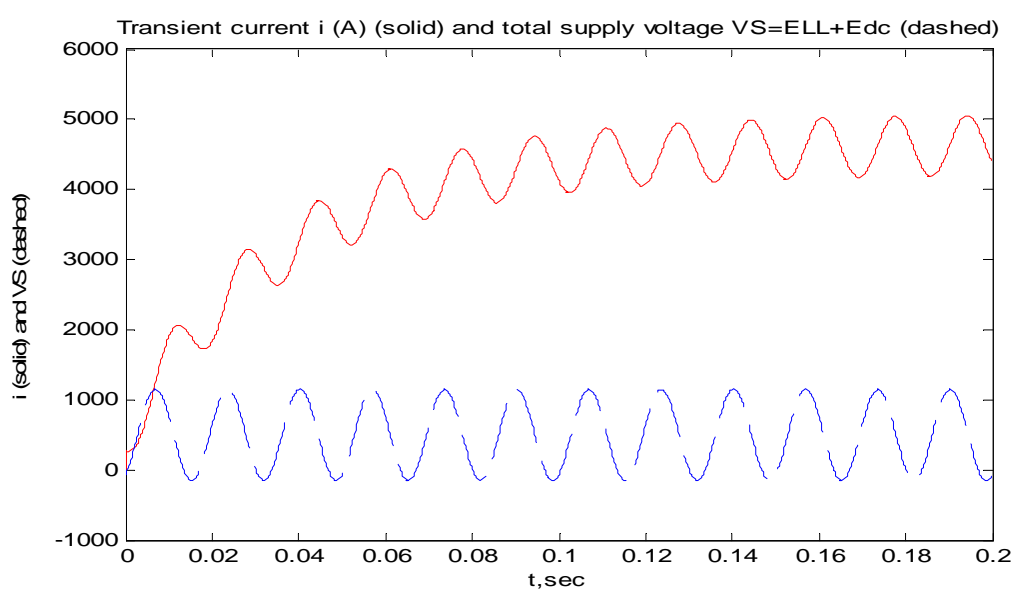

Figure 4. The transient current and fuse voltage if only one fuse in series with the semiconductor device at F1 was used to clear the circuit.
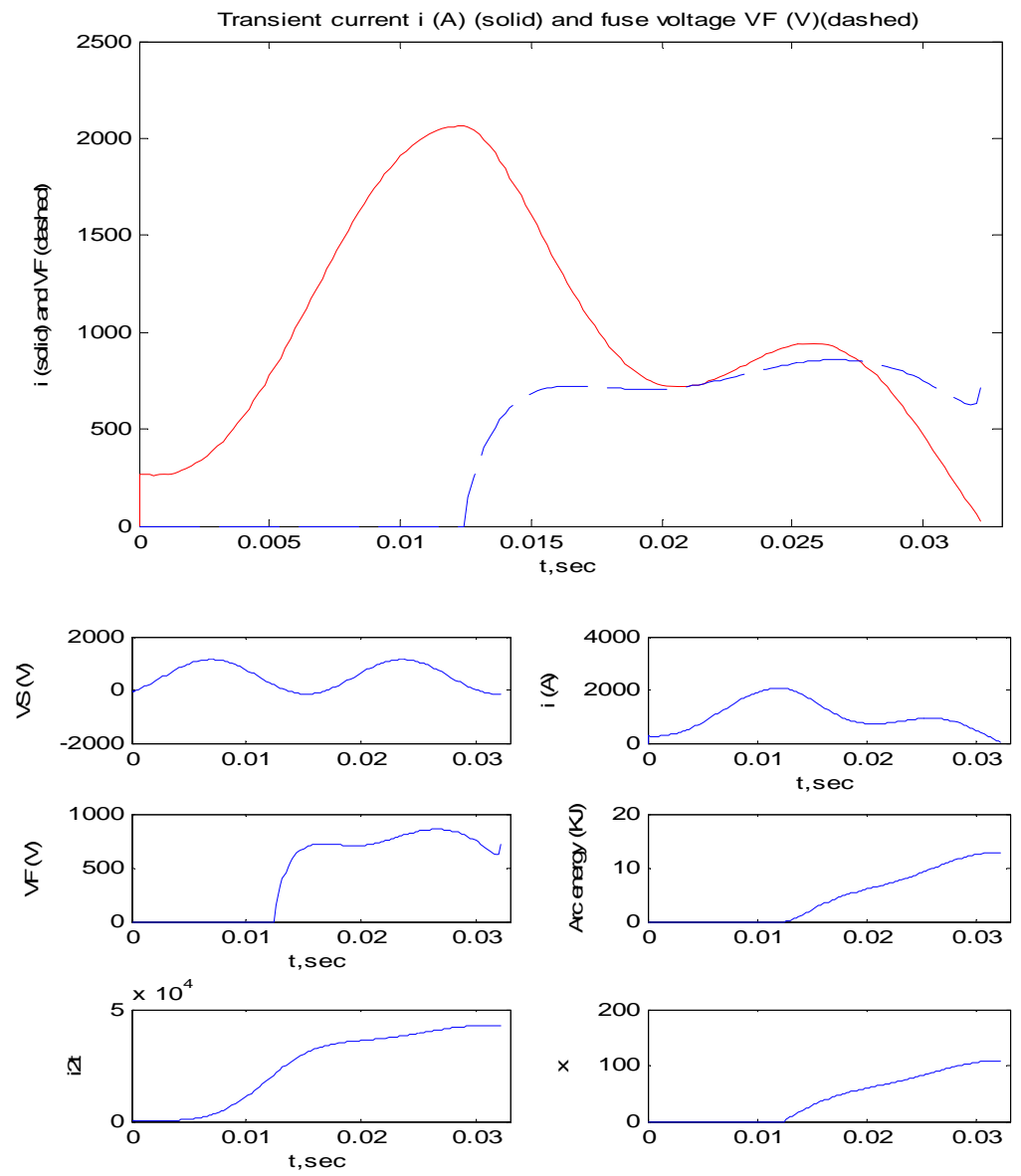


\section{The Effect of the Motor Time Constant}

The total response to an internal commutation fault depends critically upon the DC load characteristics. The effect of varying the DC machine time constant has been investigated within the range of 1-100 ms. Figure 5 shows the variation of the arc energy $(\mathrm{kJ})$ and fuse voltage versus the DC machine time constant when the 200 A fuse used as F1 and F2. Figure 6 shows the variation of the current at start of arcing (A), peak arcing current (A), pre-arcing time (ms) and arcing duration (ms) versus the DC machine time constant used when the 200 A fuse was used in both locations. Figure 7 shows the variation of the arc energy versus arc-angle and arc-angle versus the DC machine time constant when the 200 A fuse used as F1 and F2. It is clear that increasing the time constant will increase the arc-angle, pre-arcing time and arcing duration. The minimum range for peak fuse voltage, arc energy, starting and peak prospective currents will occur at the mid range of motor time constant starting from $20 \mathrm{~ms}$ to $50 \mathrm{~ms}$. Table 2 summarizing the minimum and maximum of the fuse simulation results.

Figure 5. Variation of the arc energy $(\mathrm{kJ})$ and peak fuse voltage $(\mathrm{V})$ versus the DC machine time constant (ms) when the 200 A fuse used as F1 and F2.

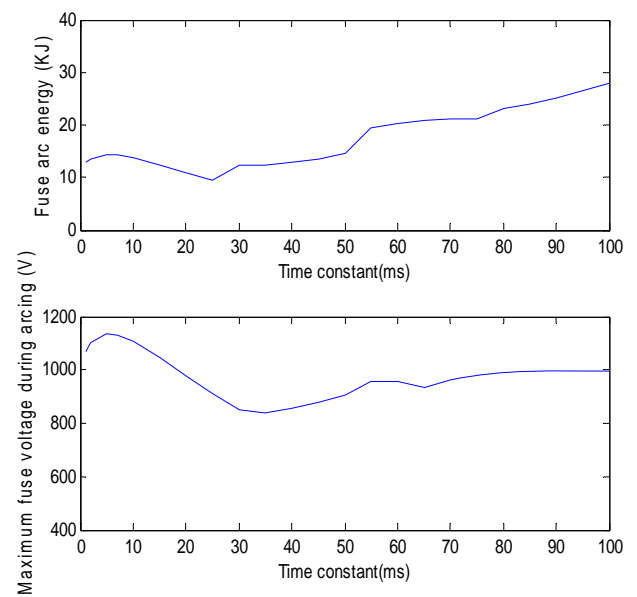

Fuse used as F1

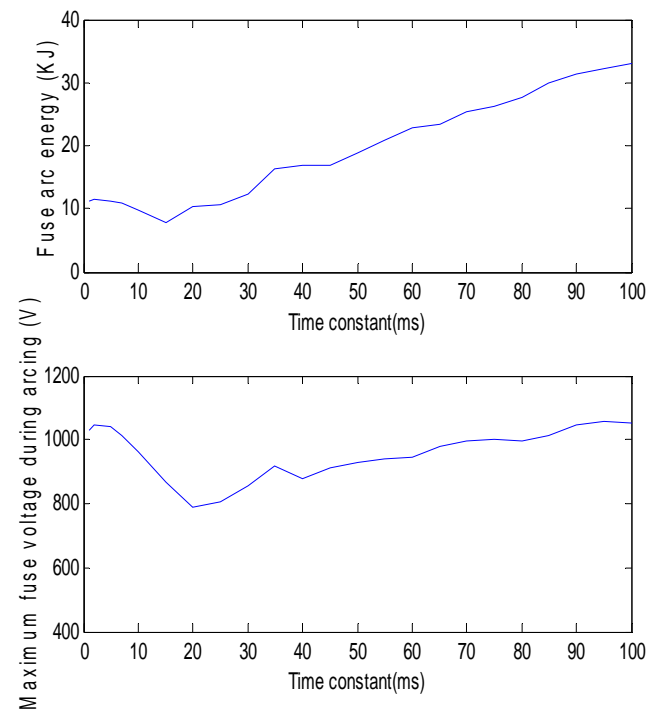

Fuse used as F2 
Figure 6. Variation of the current at start of arcing (A), peak arcing current (A), pre-arcing time (ms) and arcing duration (ms) versus the DC machine time constant (ms) when the 200 A fuse used as F1 and F2.
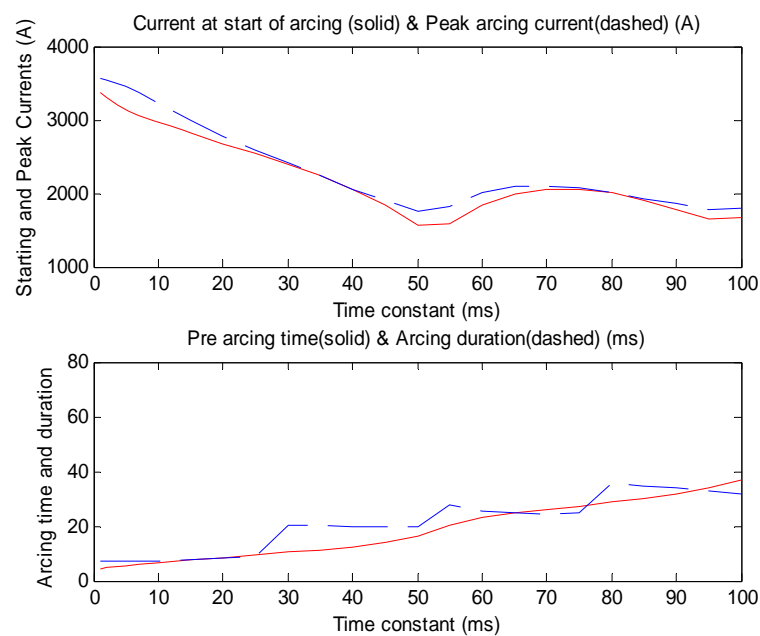

Fuse used as F1
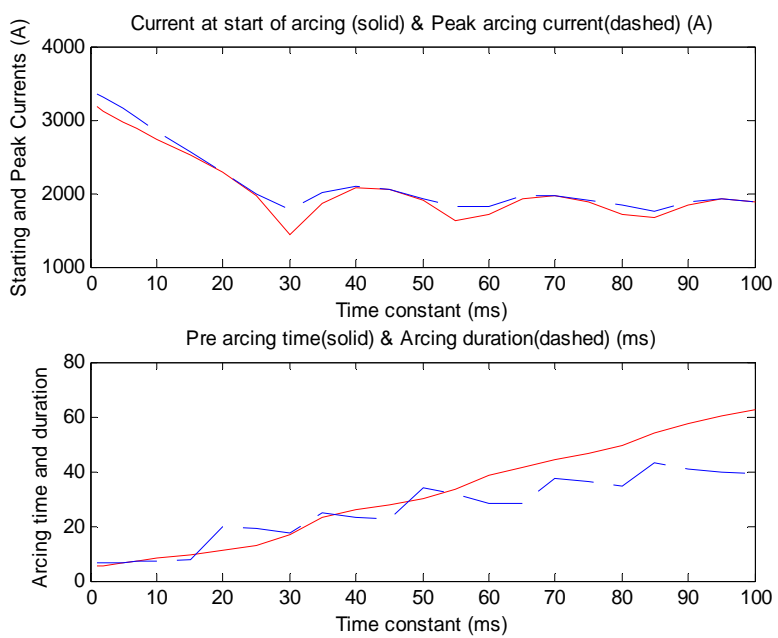

Fuse used as F2

Table 2. Lists of the minimum and maximum values for arc energy, peak fuse voltage, the current at start of arcing, peak prospective current, pre-arcing time, arcing duration, arcangle and the time constant at which the minimum and maximum occurred.

\begin{tabular}{|c|c|c|c|c|}
\hline & $\begin{array}{c}\text { Minimum when } \\
\text { fuse used as F1 }\end{array}$ & $\begin{array}{l}\text { Minimum when } \\
\text { fuse used as F2 }\end{array}$ & $\begin{array}{l}\text { Maximum when } \\
\text { fuse used as F1 }\end{array}$ & $\begin{array}{l}\text { Maximum when } \\
\text { fuse used as F2 }\end{array}$ \\
\hline $\begin{array}{c}\text { Arc energy } \\
(\mathbf{k J})\end{array}$ & $\begin{array}{c}9.483 \\
\text { tc }=25 \\
\text { arc-angle }=143.7\end{array}$ & $\begin{array}{c}7.8012 \\
\text { tc }=15 \\
\text { arc-angle }=146.0\end{array}$ & $\begin{array}{c}27.857 \\
\text { tc }=100 \\
\text { arc-angle }=739.92\end{array}$ & $\begin{array}{c}32.99 \\
\text { tc }=100 \\
\text { arc-angle }=1292.57\end{array}$ \\
\hline $\begin{array}{c}\text { Peak fuse } \\
\text { voltage during } \\
\text { arcing }(\mathrm{V}) \\
\end{array}$ & $\begin{array}{l}839.066 \\
\text { tc }=35\end{array}$ & $\begin{array}{l}786.11 \\
\text { tc }=20\end{array}$ & $\begin{array}{c}1135.19 \\
\text { tc }=5\end{array}$ & $\begin{array}{l}1058.67 \\
\text { tc }=95\end{array}$ \\
\hline $\begin{array}{l}\text { Current at start } \\
\text { of arcing (A) }\end{array}$ & $\begin{array}{l}1564.93 \\
\text { tc }=50\end{array}$ & $\begin{array}{l}1431.82 \\
\text { tc }=30\end{array}$ & $\begin{array}{c}3362.02 \\
\text { tc }=1\end{array}$ & $\begin{array}{c}3188.17 \\
\text { tc }=1\end{array}$ \\
\hline $\begin{array}{c}\text { Peak current } \\
\text { (A) }\end{array}$ & $\begin{array}{c}1763.0584 \\
\text { tc }=50\end{array}$ & $\begin{array}{c}1761.5082 \\
\text { tc }=85\end{array}$ & $\begin{array}{c}3572.9581 \\
\text { tc }=1\end{array}$ & $\begin{array}{c}3359.3621 \\
\text { tc }=1\end{array}$ \\
\hline $\begin{array}{c}\text { Pre-arcing time } \\
\text { (ms) }\end{array}$ & $\begin{array}{c}4.39 \\
\text { tc }=1\end{array}$ & $\begin{array}{c}5.19 \\
\mathrm{tc}=1\end{array}$ & $\begin{array}{c}37.03 \\
\text { tc }=100\end{array}$ & $\begin{array}{l}62.6193 \\
\mathrm{tc}=100\end{array}$ \\
\hline $\begin{array}{l}\text { Duration of } \\
\text { arcing (ms) }\end{array}$ & $\begin{array}{l}7.0474 \\
\text { tc }=5 \\
\end{array}$ & $\begin{array}{l}6.7122 \\
\mathrm{tc}=2\end{array}$ & $\begin{array}{l}35.5435 \\
\text { tc }=80\end{array}$ & $\begin{array}{l}43.220 \\
\text { tc }=85\end{array}$ \\
\hline Arcing angle & $\begin{array}{c}35.0123 \\
\mathrm{tc}=1\end{array}$ & $\begin{array}{c}52.2041 \\
\text { tc }=1\end{array}$ & $\begin{array}{c}739.9 \\
\text { tc }=100\end{array}$ & $\begin{array}{c}1292.5779 \\
\text { tc }=100\end{array}$ \\
\hline
\end{tabular}

When the fuse in AC line (F2) it will reach higher level of arc-angle compared when the fuse with semiconductor devices. Generally, the most desirable range of arcing angle for fuse to produce melting is between 90-270, or 450-630 (i.e. falling part of AC voltage). If the arc-angle $\psi$ falls within the range 0 to 90 degrees, the fuse will melt on the rising part of voltage waveform. If fuse melts within 60 
and 90, arcing will occur during a period of time when AC supply voltage near the peak value. This range of $\psi$ will be called critical melting zone. There is another critical melting zone between 420 and 450. Melting mostly will occur in the first critical zone when motor time constant less than $10 \mathrm{~ms}$, and to obtain melting in the second critical zone the time constant shall be increased beyond $50 \mathrm{~ms}$, especially from $52-58 \mathrm{~ms}$. This is found for both fuse location.

Figure 7. Variation of the arc energy $(\mathrm{kJ})$ versus arc-angle (degree) and arc-angle (degree) versus the DC machine time constant (ms) when the 200 (A) fuse used as F1 and F2.
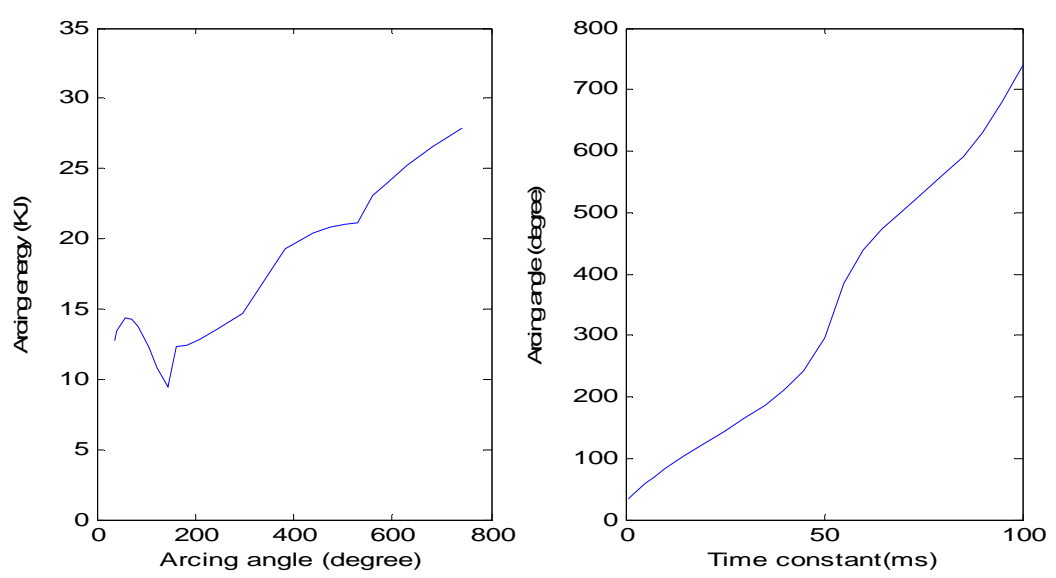

Fuse used as F1
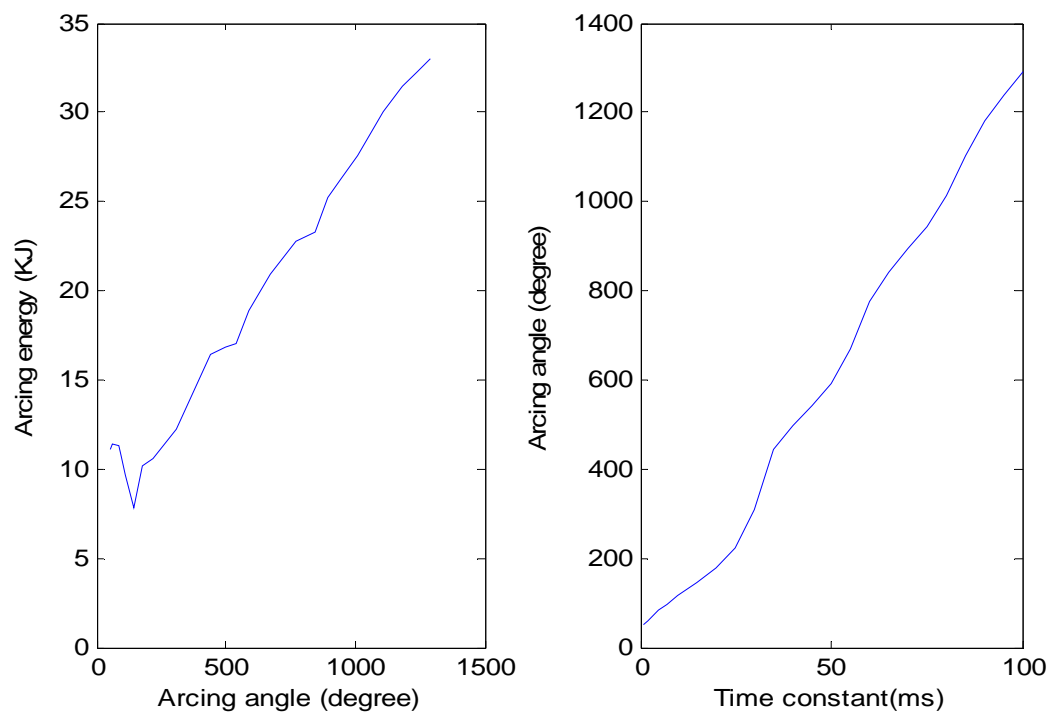

Fuse used as F2

\section{The Effect of Number of Fuses}

It is recommended that two fuses in series clear the fault. Treatment of two fuses in series sharing the breaking duty in a ratio of $f=(1-f)$, where $f=0.5$ and $f=0.6$ was carried out in this study, where $f$ is the fraction of the total energy or voltage taken by one of the two fuses. The governing equation in this case: 


$$
\frac{d i}{d t}=\frac{V_{s}-R i-\frac{1}{f} V_{f}}{L}
$$

Voltage across fuse $1=V_{f}$ and across the fuse $2=[(1-f) / f] V_{f}$

The share of total calculated energy equals $f$ for fuse 1 and (1-f) for fuse 2 . The comparison here was made for a motor with time constant $40 \mathrm{~ms}$ and supply impedance $0.05 \mathrm{p}$.u when having

- One 200 A fuse located at F1 ( $f=1)$

- One 200 A fuse located at F2 ( $\mathrm{f}=1)$

- Two 200 A fuses located at F1 and sharing the breaking duty equally ( $f=0.5)$

- Two 200 A fuses located at F1 sharing the breaking duty in a ratio 0.6:0.4 $(f=0.6)$

Table 3 lists the arc energy, peak fuse voltage, current at start of arcing, peak arcing current, prearcing time, arcing duration, arc-angle and total arc energy for each case when the motor with time constant $=40 \mathrm{~ms}$ and supply impedance $=0.05$.

Table 3. Lists the arc energy, peak fuse voltage, current at start of arcing, peak arcing current, pre-arcing time, arcing duration, arc-angle and total arc energy.

\begin{tabular}{|c|c|c|c|c|}
\cline { 2 - 5 } \multicolumn{1}{c|}{} & $\begin{array}{c}\text { One 200A fuse } \\
\text { used as F1, f= 1 }\end{array}$ & $\begin{array}{c}\text { One 200A fuse } \\
\text { used as F2, f= 1 }\end{array}$ & $\begin{array}{c}\text { Two 200A fuses } \\
\text { used as F1, f = 0.5 }\end{array}$ & $\begin{array}{c}\text { Two 200A fuses } \\
\text { used as F1, f = 0.6 }\end{array}$ \\
\hline $\begin{array}{c}\text { Arc energy } \\
\text { (kJ) }\end{array}$ & 12.8722 & 16.7950 & 2.0609 & 3.3757 \\
\hline $\begin{array}{c}\text { Peak fuse } \\
\text { voltage during } \\
\text { arcing (V) }\end{array}$ & 857.6595 & 876.6067 & 629.3049 & 654.6958 \\
\hline $\begin{array}{c}\text { Current at } \\
\text { start of arcing } \\
\text { (A) }\end{array}$ & 2060.5463 & 2065.6563 & 2060.5463 & 2060.5463 \\
\hline $\begin{array}{c}\text { Peak current } \\
\text { (A) }\end{array}$ & 2062.2832 & 2100.6173 & 2062.2832 & 2062.2832 \\
\hline $\begin{array}{c}\text { Pre-arcing } \\
\text { time (ms) }\end{array}$ & 12.5337 & 25.8190 & 12.5337 & 12.5337 \\
\hline $\begin{array}{c}\text { Duration of } \\
\text { arcing (ms) }\end{array}$ & 19.7847 & 23.1904 & 15.9757 & 16.8648 \\
\hline Arcing angle & 210.7284 & 497.6897 & 210.7284 & 210.7284 \\
\hline $\begin{array}{c}\text { Arc energy } \\
\text { (kJ) }\end{array}$ & 12.8722 & 16.7950 & 4.1219 & 5.6262 \\
\hline
\end{tabular}

It can be noted that when one fuse alone clears the circuit, the arc energy and peak fuse voltage during arcing produced for internal commutation fault is high. When there are two fuses either sharing the breaking duty equally ( $\mathrm{f}=0.5$ ) or the voltage is split in the ratio $\mathrm{f}=0.6$, the arc energy and peak fuse voltage are reduced significantly. The pre-arcing time, current at start of arcing, peak prospective current and arc angle were not affected by the number of fuses. 


\section{The Effect of Supply Impedance}

The percentage value of supply impedance plays an important role for total response of the commutation fault. Here, the supply impedance was varied from $X=0.01$ p.u to $X=0.4$ p.u. Table 4 lists the maximum and minimum values for arc energy, fuse voltage, the current at start of arcing, peak prospective current, pre-arcing time, arcing duration, arc-angle and the system impedance at which the maximum and minimum occurred when $200 \mathrm{~A}$ fuse located at F1 and the motor time constant is $40 \mathrm{~ms}$. Their values when the system impedance $=0.05$ and 0.15 are listed also. Figures 8 and 9 show the variations as the system impedance varied from $Z=0.01$ p.u to $Z=0.4$ p.u.

Table 4. Lists the maximum and minimum values for arc energy, fuse voltage, the current at start of arcing, peak prospective current, pre-arcing time, arcing duration, arc-angle and the system impedance.

\begin{tabular}{|c|c|c|c|c|}
\hline & $Z=0.05$ p.u & $X=0.15$ p.u & $\begin{array}{l}\text { Minimum when } \\
\text { fuse used as F1 }\end{array}$ & $\begin{array}{c}\text { Maximum when } \\
\text { fuse used as F1 }\end{array}$ \\
\hline $\begin{array}{c}\text { Arc energy } \\
(\mathbf{k J})\end{array}$ & 12.8722 & 12.5666 & $\begin{array}{c}12.5666 \\
\mathrm{Zpu}=0.15 \\
\text { arc-angle }=272\end{array}$ & $\begin{array}{c}15.6684 \\
\mathrm{Zpu}=0.25 \\
\text { arc-angle }=437.47\end{array}$ \\
\hline $\begin{array}{l}\text { Peak fuse voltage } \\
\text { during arcing (V) }\end{array}$ & 857.6595 & 857.1913 & $\begin{array}{c}831.6888 \\
\mathrm{Zpu}=0.35\end{array}$ & $\begin{array}{c}900.6567 \\
\mathrm{Zpu}=0.25\end{array}$ \\
\hline $\begin{array}{c}\text { Current at start } \\
\text { of arcing (A) }\end{array}$ & 2060.5463 & 1623.6856 & $\begin{array}{c}1425.9338 \\
\mathrm{Zpu}=0.2\end{array}$ & $\begin{array}{l}2180.4415 \\
\mathrm{Zpu}=0.01\end{array}$ \\
\hline Peak current (A) & 2062.2832 & 1805.4284 & $\begin{array}{l}1701.1453 \\
\mathrm{Zpu}=0.2\end{array}$ & $\begin{array}{l}2180.5270 \\
\mathrm{Zpu}=0.01\end{array}$ \\
\hline $\begin{array}{c}\text { Pre-arcing time } \\
(\mathrm{ms})\end{array}$ & 12.5337 & 15.3723 & $\begin{array}{c}11.8 \\
\mathrm{Zpu}=0.01\end{array}$ & $\begin{array}{c}28.1323 \\
\mathrm{Zpu}=0.4\end{array}$ \\
\hline $\begin{array}{c}\text { Duration of arcing } \\
\text { (ms) }\end{array}$ & 19.7847 & 18.610 & $\begin{array}{c}18.6103 \\
\mathrm{Zpu}=0.15\end{array}$ & $\begin{array}{c}28.0284 \\
\mathrm{Zpu}=0.2\end{array}$ \\
\hline Arcing angle & 210.7284 & 272.0421 & $\begin{array}{c}195.2552 \\
\mathrm{Zpu}=0.01\end{array}$ & $\begin{array}{l}547.6584 \\
\mathrm{Zpu}=0.4\end{array}$ \\
\hline
\end{tabular}

It can be noted that increasing the system impedance will not affect the arc energy or peak fuse voltage during arcing. The arc angle and pre-arcing time increase with the supply impedance in very small range. The current at start of arcing and peak prospective current will be reduced as system impedance increased, but will increase again as $Z>0.2$ p.u. 
Figure 8. Variation of the arc energy (kJ) and fuse voltage (V), current at start of arcing (A), peak arcing current (A), pre arcing time (ms) and arcing duration (ms) versus the supply impedance when the 200 A fuse used as F1.
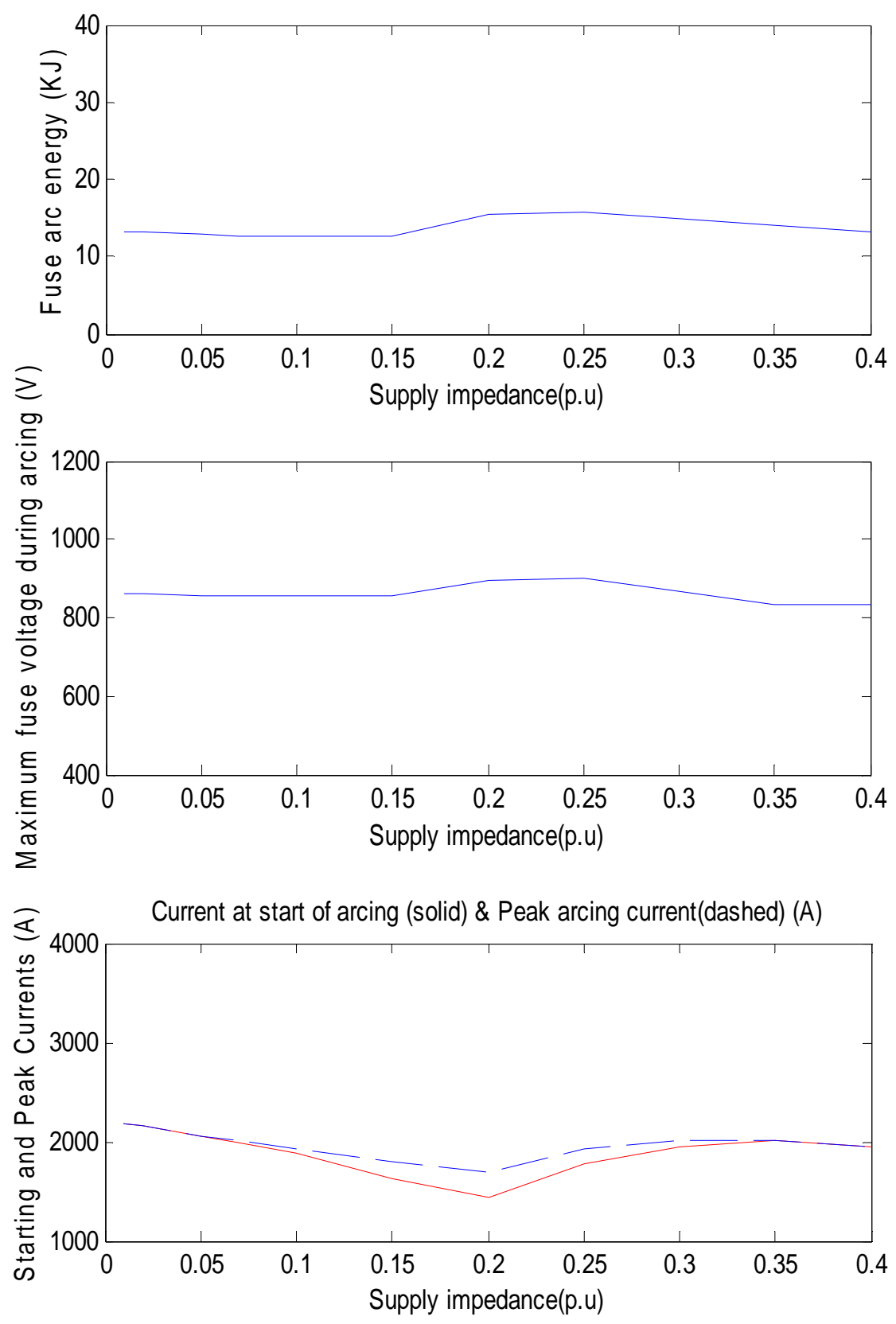

Pre arcing time(solid) \& Arcing duration(dashed) (ms)

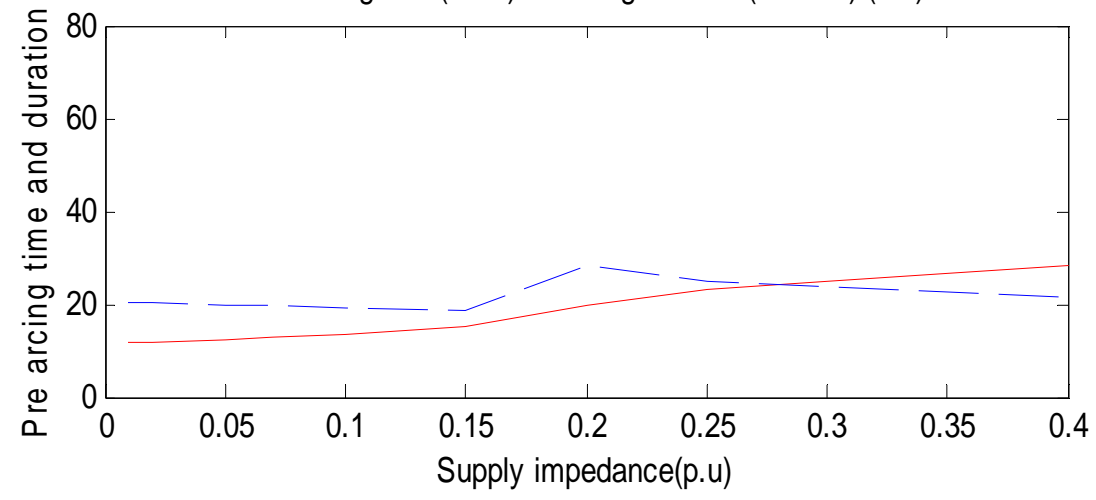


Figure 9. Variation of the arc energy versus arc-angle and arc-angle versus the supply impedance when the 200 A fuse used as F1.
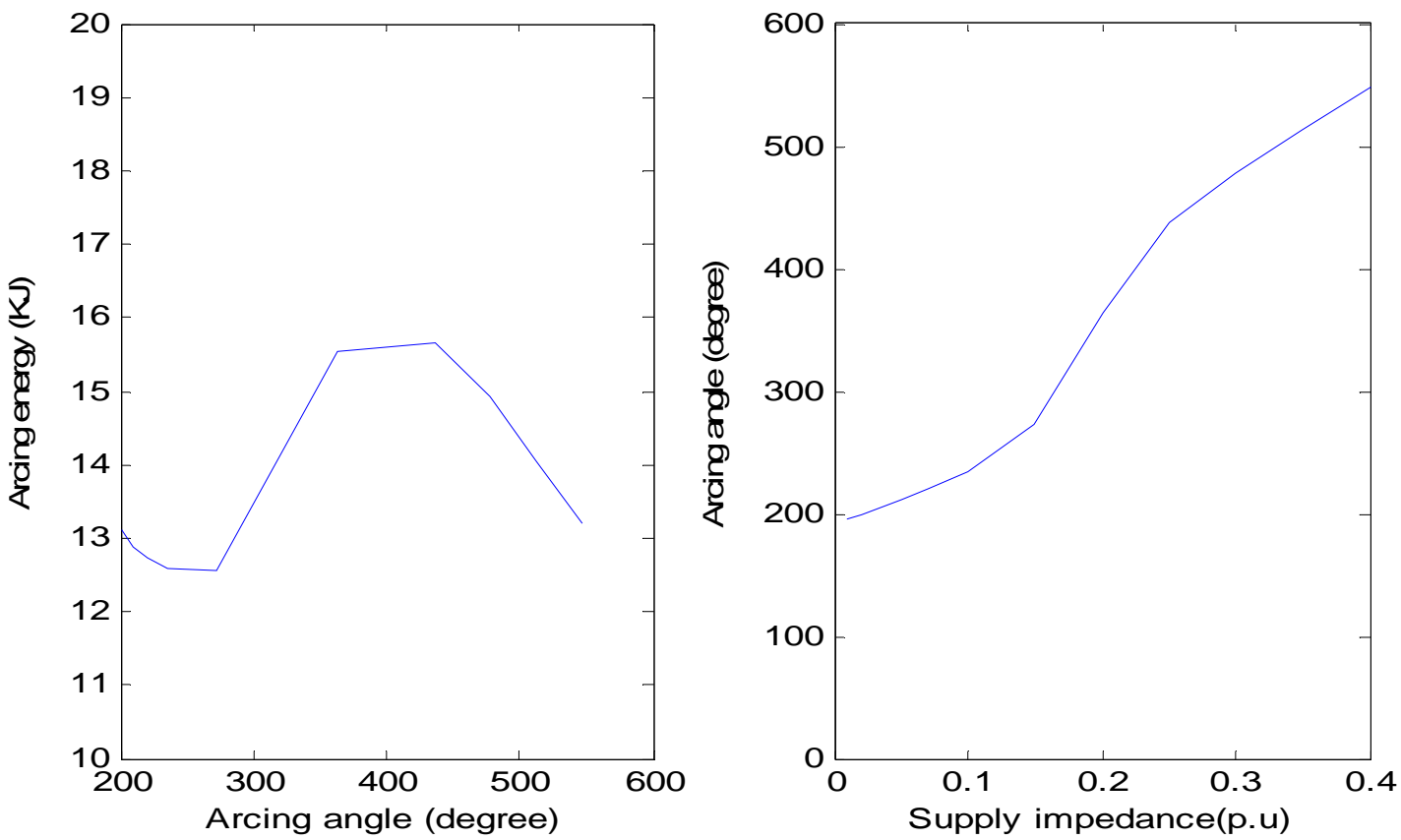

Table 5. Summary of the simulation results.

\begin{tabular}{|c|c|c|c|c|c|c|c|c|c|c|c|}
\hline $\begin{array}{c}\text { Motor } \\
\text { HP }\end{array}$ & $\begin{array}{l}\text { Con. } \\
\text { Rat } \\
(\mathrm{kW})\end{array}$ & $I_{d c}$ & $\begin{array}{c}\text { MPFR } \\
I_{F 1}\end{array}$ & FAR & $\begin{array}{c}\text { Melting } \\
i^{2} t\end{array}$ & $\begin{array}{l}\text { Arc-angle } \\
\text { (degree) }\end{array}$ & $\begin{array}{c}\text { Pre-arc } \\
\text { time }(\mathrm{ms})\end{array}$ & $\begin{array}{l}\text { Current at } \\
\text { start } \\
\text { of arcing } \\
\text { (A) }\end{array}$ & $\begin{array}{l}\text { Peak } \\
\text { current } \\
\text { (A) }\end{array}$ & $\begin{array}{c}\text { Peak } \\
\text { voltage } \\
\text { during } \\
\text { arcing }(\mathrm{V})\end{array}$ & $\begin{array}{c}\text { Arc } \\
\text { energy } \\
(\mathrm{kJ})\end{array}$ \\
\hline 25 & 18.6 & 39 & 28 & 35 & 120 & 342.0 & 18.6 & 249.9 & 402.27 & 633.22 & 6.663 \\
\hline 50 & 37.3 & 79 & 57 & 60 & 360 & 219.2 & 12.92 & 600.1 & 604.394 & 594.54 & 8.157 \\
\hline 100 & 74.6 & 157 & 113 & 125 & 1600 & 244.4 & 14.09 & 1154.2 & 1199.17 & 722.06 & 11.22 \\
\hline 150 & 111. & 235 & 170 & 175 & 3100 & 214.5 & 12.70 & 1790.6 & 1794.95 & 826.52 & 11.81 \\
\hline 170 & 127 & 270 & 194 & 200 & 4000 & 210.7 & 12.53 & 2060.5 & 2062.28 & 857.65 & 12.87 \\
\hline 200 & 149 & 314 & 227 & 250 & 6200 & 236.6 & 13.73 & 2338.0 & 2398.35 & 922 & 14.94 \\
\hline 250 & 186 & 393 & 283 & 300 & 9000 & 221.0709 & 13.01 & 2981.2 & 3001.76 & 944.98 & 16.37 \\
\hline 325 & 242 & 510 & 368 & 400 & 16000 & 231.8 & 13.51 & 3823.6 & 3895.42 & 1041.39 & 19.23 \\
\hline 425 & 317 & 667 & 481 & 500 & 25000 & 214.6 & 12.71 & 5082.0 & 5094.60 & 1261.1 & 21.82 \\
\hline 525 & 391 & 825 & 595 & 600 & 36000 & 205.0 & 12.27 & 6301.4 & 6301.42 & 1453.64 & 22.63 \\
\hline 625 & 466 & 982 & 708 & 800 & 64000 & 250.4 & 14.37 & 7139.1 & 7500.60 & 1503.64 & 28.68 \\
\hline Minimum & & $\begin{array}{c}39 \text { at } \\
\mathrm{HP}=25\end{array}$ & $\begin{array}{c}28 \text { at } \\
\mathrm{HP}=25\end{array}$ & $\begin{array}{c}35 \text { at } \\
\mathrm{HP}=25\end{array}$ & $\begin{array}{c}120 \text { at } \\
\mathrm{HP}=25\end{array}$ & $\begin{array}{c}205.0 \\
\mathrm{HP}=525\end{array}$ & $\begin{array}{c}12.27 \\
\mathrm{HP}=525\end{array}$ & $\begin{array}{c}249.9 \\
\mathrm{HP}=25\end{array}$ & $\begin{array}{c}402.27 \\
\mathrm{HP}=25\end{array}$ & $\begin{array}{c}594.5 \\
\mathrm{HP}=50\end{array}$ & $\begin{array}{c}6.66 \\
\mathrm{HP}=25^{\mathrm{a}}\end{array}$ \\
\hline Maximum & & $\begin{array}{c}982 \text { at } \\
\mathrm{HP}=625\end{array}$ & $\begin{array}{c}708 \text { at } \\
\mathrm{HP}=625\end{array}$ & $\begin{array}{c}800 \\
\mathrm{HP}=625\end{array}$ & $\begin{array}{l}64000 \text { at } \\
\mathrm{HP}=625\end{array}$ & $\begin{array}{c}342.08 \\
\mathrm{HP}=25\end{array}$ & $\begin{array}{c}18.61 \\
\mathrm{HP}=25\end{array}$ & $\begin{array}{c}7139.1 \\
\mathrm{HP}=625\end{array}$ & $\begin{array}{c}7500.60 \\
\mathrm{HP}=625\end{array}$ & $\begin{array}{c}1504 \\
\mathrm{HP}=625\end{array}$ & $\begin{array}{c}28.6 \\
\mathrm{HP}=625^{\mathrm{b}}\end{array}$ \\
\hline
\end{tabular}

${ }^{\mathrm{a}}$ at arc-angle $=342.08$;

${ }^{b}$ at arc-angle $=250.49$ 


\section{The Effect of DC Machine Rating}

The above analysis was done for a range of DC machines with different power rating from $25 \mathrm{HP}$ to $625 \mathrm{HP}$ with the fuse located in series with the semiconductor device (F1). The converter rating in $\mathrm{kW}$ will be machine HP*746. The machine time constant is $40 \mathrm{~ms}$ and supply impedance $=0.05 \mathrm{p} . \mathrm{u}$ were considered. Table 5, Figures 10 and 11 summarize some of the results. It can be seen that increasing the machine and fuse ratings will increase the level of fuse voltage, starting and peak prospective currents and arc energy to higher level. The arc-angle and pre arcing time generally will not be affected. The arcing duration will decrease sharply as the machine rating increases in the lowest range of machine rating. An adequate voltage rating for fuses protecting the regenerative DC drives can be the AC line-line supply voltage.

Figure 10. Variation of the arc energy $(\mathrm{kJ})$ and fuse voltage $(\mathrm{V})$, current at start of arcing (A), peak arcing current (A), pre arcing time(ms) and arcing duration (ms) versus the DC machine HP when 200 A fuse used as F1.
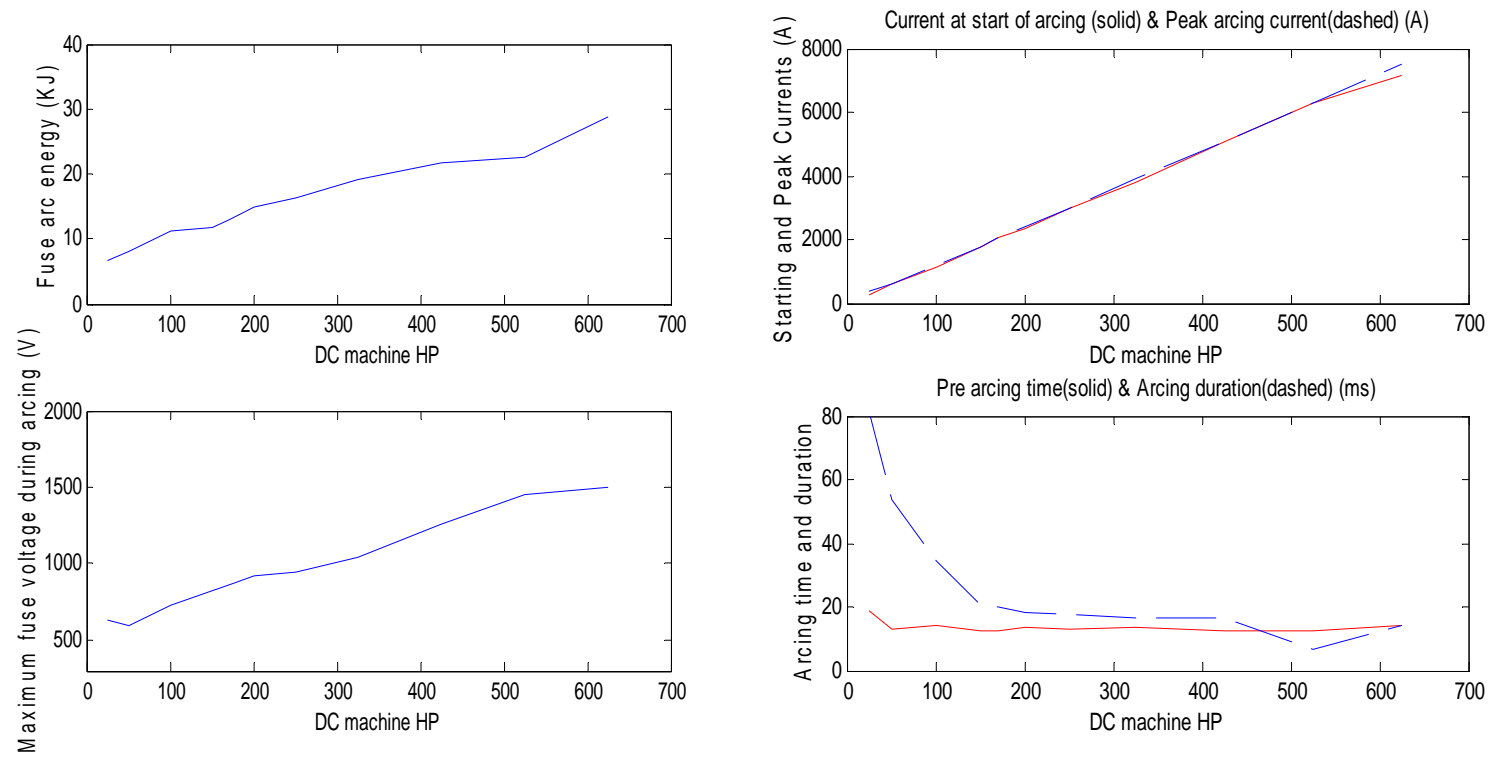

Figure 11. Variation of the arc energy versus arc-angle and arc-angle versus the DC machine HP when the 200 A fuse used as F1.
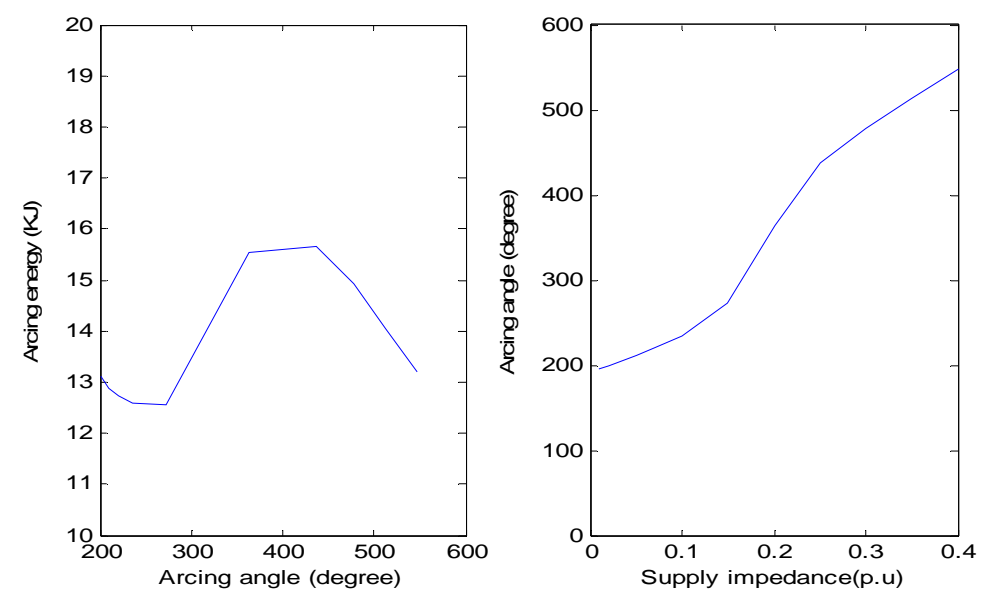


\section{Conclusions}

In this paper the effect of varying different parameters to the total response for fuses protecting against the regenerative circuit internal commutation fault was investigated. The effect of varying the motor time constant, supply impedance, number of fuses used to clear the fault and DC machine rating was studied. The model of 200 A fuses was employed in this study and fuses in series with the semiconductor devices (F1) and fuses in AC line (F2) were both considered. The results gained were put side by side with results obtained in references [4] and [6].

It was concluded from the study that the location of the same fuse, whether it is in series with the semiconductor devices (F1) or in the AC line, will affect the loading condition of the DC machine $I_{d c}$. The percentage value of supply impedance and DC machine time constant play an important role for the total response of internal commutation fault. The stress on fuse within the range of mid DC machine time from $20 \mathrm{~ms}$ to $50 \mathrm{~ms}$ is not severe. However within the range $0-10 \mathrm{~ms}$ and beyond $50 \mathrm{~ms}$ melting can occur in the critical melting zones which are severe condition. Varying the supply impedance will affect mainly the current at start of arcing and peak prospective current. If one fuse alone clears the circuit, the arc energy produced for internal commutation fault is high. When there are two fuses either sharing the breaking duty equally or the voltage is split in a ratio of 0.6:0.4, where the arc energy reduced significantly. An adequate voltage rating for fuses protecting the regenerative DC drives is the AC line-line supply voltage. Increasing the DC machine and fuse ratings will increase the level of fuse voltage, starting and peak prospective currents and arc energy to higher level.

\section{References}

1. Bussière, W.; Rochette, D.; Velleaud, D.; Latchimy, J.; Gelet, G.; Gentils, F.; Perez-Quesada, J.C.; Rambaud, T.; André, T. Experimental study of HBC fuses working at short and medium pre-arcing times. J. Phys. D: Appl. Phys. 2008, 41, 195210:1-195210:13.

2. Wilkins, R.; Cline, H.C. An advanced application tool to enhance the fuse protection of power semiconductors. In IEEE Industry Applications Society Annual Meeting, Toronto, Canada, October 1993.

3. Wilkins, R.; Stevenson, R. Characteristics of modern semiconductor - protection fuses. In Drives/Motors/Controls Tutorial update, Birmingham, UK, November 1987.

4. Memiaghe, S.; Bussiere, W.; Rochette, D.; Touzani, R.; Andre, P. Pre-arcing times in HBC fuse for high fault currents. Comparison between simulation and experimental. High. Temp. Mat. Proc. 2008, 12, 345-364.

5. High speed fuse application guides. In Bussmann circuit protection solutions; Copper Industries Group, Burton-on-the Wolds: Leicestershire, UK, 2008.

6. Psomopoulos. S.; Karag nnopoulos, C.G. Temperature distribution of fuse elements during the pre-arcing period. Electr. Power Syst. Res. 2002, 61, 161-167.

7. Gnanalingam, S.; Wilkins, R. Digital simulation of fuses breaking tests. IEEE Proc. 1980, 127, 434-440.

8. Wilkins, R. Generalised short-circuit characteristics for HRC fuses. IEEE Proc. 1975, 122, 1289-1294. 
9. Wilkins, R. Computer modelling of fuse breaking tests. In IIE Workshop, Cocoyoe, Mexico, 1993.

10. Wilkinson, A.L. Use of semiconductor - protection fuses on DC. Drives/Motors/Controls Tutorial update, Birmingham, UK, November 1987.

11. Sperow, L.H. Fuse selection for power semiconductor conversion equipment. IEEE Trans. Ind. Appl. 1973, IA-9, 33-40.

(C) 2009 by the authors; licensee Molecular Diversity Preservation International, Basel, Switzerland. This article is an open-access article distributed under the terms and conditions of the Creative Commons Attribution license (http://creativecommons.org/licenses/by/3.0/). 